
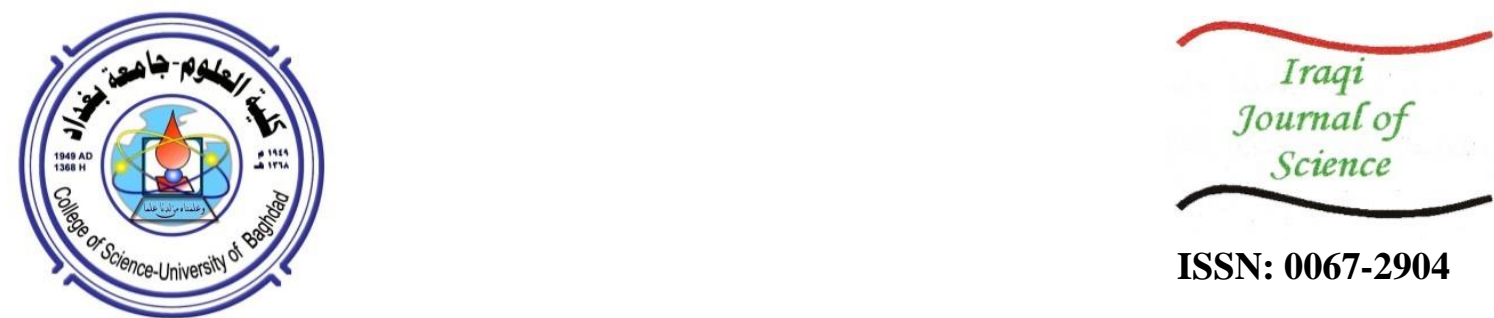

ISSN: 0067-2904

\title{
Estimation of Hematological Parameters of Disease Severity in Iraqi Patients with COVID-19
}

\author{
Zainab S. Mahmood ${ }^{1}$, Hula Y. Fadhil ${ }^{1 *}$, Ali H Ad'hiah ${ }^{2}$ \\ ${ }^{I}$ Department of biology, college of science, university of Baghdad, Baghdad, Iraq \\ ${ }^{2}$ Tropical biological research unit, college of science, university of Baghdad, Baghdad, Iraq
}

Received: $15 / 5 / 2021$

Accepted: 4/7/2021

\begin{abstract}
Coronavirus disease 2019 (COVID-19) is a systemic disease with a substantial impact on the hematopoietic system and hemostasis. Neutrophilia is an early indicator of SARS-CoV-2 infection, while lymphopenia acts as a biomarker of the severity of infection, and the neutrophil-to-lymphocyte ratio (NLR) is the main indicator of cytokine storms. Thus, this study aimed to provide local data about hematological parameters among COVID-19 patients and estimate their correlation with viral load and other factors in severe cases. A total of 99 nasopharyngeal swabs and whole blood specimens were collected from individuals suspected with COVID19 between October and December 2020. Samples were tested by real time reverse transcriptase polymerase chain reaction (rRT-PCR) assay, COVID-19 IgG and IgM antibody tests, beside hematological analysis. The results showed a significant increase in neutrophils count and NLR, correlated with the severity of the disease Patients at older ages who are suffering from some comorbidity like hypertension and diabetes are at elevated risk to develop more severe disease outcome. The findings demonstrated a higher neutrophils count and higher death ratio in older ages. Also, the results suggest that NLR could be employed as a useful biomarker and potential prognostic tool supporting the importance of laboratory records in assessing case severity and disease progression.
\end{abstract}

Keywords: SARS- CoV-2, Ct value, biomarkers, rRT-PCR, FREND IgM/IgG antibody, NLR.

\section{تقدير المعلمات الدموية لتدهور المرض في المرضى العراقيين المصابين بكوفيد-19}

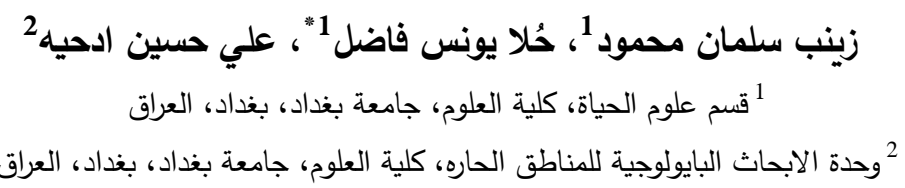

الخلاصة

يعد مرض فيروس كورونا 2019 (كوفيد-19) اصابة جهازية لها تأثير كبير على مكونات وتدفق الدم، الزيادة

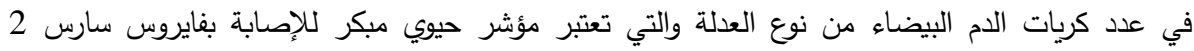

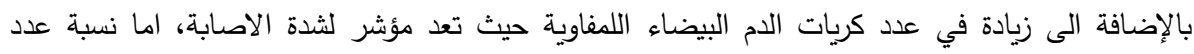

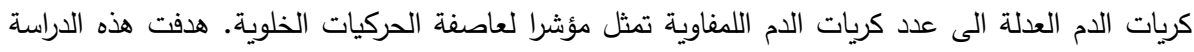

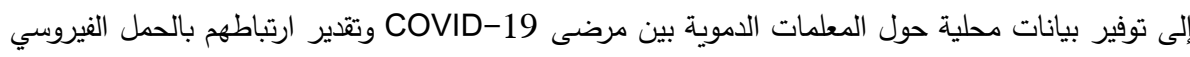

في الحالات الثديدة، فضلا عن عوامل أخرى في تدهور المرض. جمعت الثرات 99 مسحة من البلعوم الأنفي وعينة

*Email: hula.younis@ sc.uobaghdad.edu.iq 


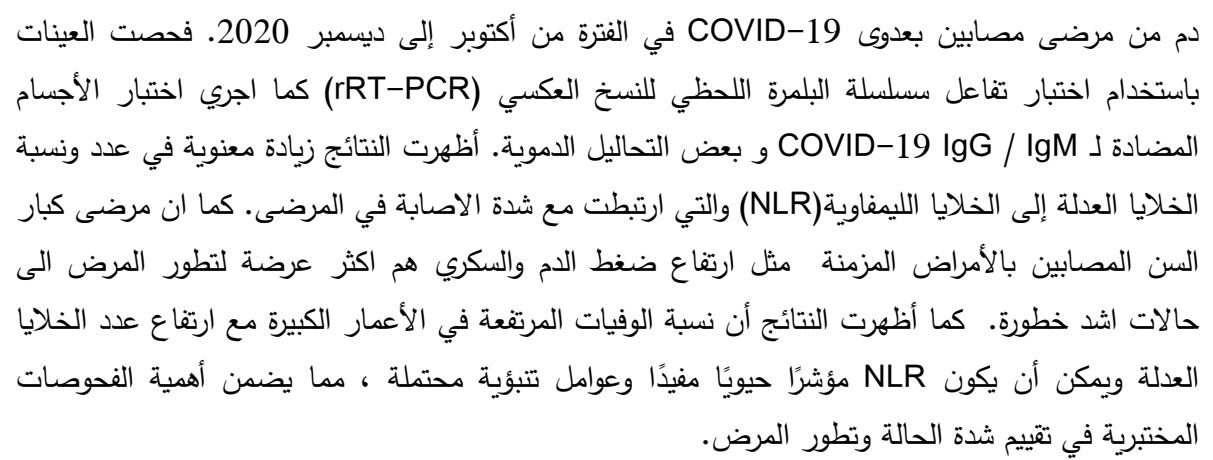

\section{Introduction}

In patients with the novel SARS-CoV-2 infection, symptoms associated with pneumonia, including fever, cough, shortness of breath, sputum formation, and myalgia or fatigue, have mainly been shown [1]. This implies that SARS-CoV-2 mostly induces acute respiratory disease in the respiratory tract. SARS-CoV-2 infection, however, can cause symptoms of other tissue-related diseases, such as those of the digestive (diarrhea, weak appetite, nausea and vomiting), nervous (confusion and headache), and cardiovascular (palmus, chest distress, and heart injury) systems [2]. Findings from 2020 stated that the clinical spectrum of COVID19 infection can be quite heterogeneous [3]. According to clinical symptoms, the World Health Organization (WHO) guidelines divided the cases into three categories depending on severity, which are mild, severe, and critical. The most characteristic clinical course of severe Coronavirus disease 2019 (COVID-19) patients is the development of acute respiratory distress syndrome (ARDS). It is a serious complication in which lungs condition causes shortage in oxygen supply from the alveoli into the blood. Hence, to increase $\mathrm{O} 2$ supply to the lungs, patients are in need of mechanical ventilators. In spite of these intensive efforts, about $40 \%$ of ARDS patients do not survive [4.[

Laboratory records, taking into account hematological, biochemical, inflammatory and immunological parameters, would help to classify COVID-19 patients into risk categories, which would be significantly important in the clinical setting and therapeutic management [5]. COVID-19 is a systemic disease with a substantial impact on the hematopoietic system and hemostasis. Neutrophilia is an early indicator of SARS-CoV-2 infection, whereas lymphopenia acts as a biomarker of the severity of infection and the neutrophil-to-lymphocyte ratio (NLR) is the main indicator of cytokine storms. One of the major problems of COVID19 outbreak is that the symptoms of disease are diverse and may result in varied manifestations among the patients [6]. In order to understand the relation of some risk factors and the difference in disease severity among COVID-19 patients, this study aimed to provide local data about hematological parameters and estimate their correlation with viral load and other factors in severe cases.

Materials and Methods

\section{1- Study population}

A total of 99 nasopharyngeal swabs and whole blood samples were collected from individuals attending Baghdad Teaching Hospital, Baghdad, Iraq, between October to December 2020, who were suspected of COVID-19 infection according to clinical signs and diagnosis of the consultant physician. These samples belonged to 50 males and 49 females. The college of science research ethics committee approved the study protocol (University of Baghdad) (Reference: CSEC/0920/0017). The respiratory tract swabs were collected in and screw capped containers that contain VTM (viral transport media) for maintaining viral viability during transportation. Nasopharyngeal swabs were stored at $-80^{\circ} \mathrm{C}$ until tested by real time reverse transcriptase polymerase chain reaction (rRT-PCR) assay for viral RNA detection. At the same time, COVID-19 IgG and IgM antibody tests were conducted for the blood samples, beside hematological analysis that included CRP and WBC differential count. 


\section{2- Molecular assay}

Viral RNA was extracted by special laboratory kit (QIAamp Viral RNA Mini kit, GmbH, Hilden, Germany) according to manufacturer's instructions. The real time reverse transcriptase PCR assay was performed for the yielded RNA using special SARS-COV-2 detection kit (DIAGNOVITAL SARS-COV-2 real time PCR kit) (all 99 samples were positive for SARS-CoV-2 as 8 samples were in 21-25 cycle threshold $(\mathrm{Ct})$ range, 34 sample in 26-30 Ct range, and 48 sample in 30-35 Ct range). For every sample, three separate wells were designated (E, RdRP, HEC). Negative NTC and positive TPC controls were prepared and $16 \mu \mathrm{l}$ of the master mix were distributed to each well in the PCR plate. $4 \mu \mathrm{l}$ of sample or control were added to respective sample and control wells. The plate was placed in the real time-PCR thermal cycler (qTOWER ${ }^{3} \mathrm{G}$ ) with the following amplification: RT step activation at $45^{\circ} \mathrm{C}$ for $20 \mathrm{~min}$, initial denaturation at $95^{\circ} \mathrm{C}$ for $10 \mathrm{~min}$, followed by 45 cycles: $95^{\circ} \mathrm{C}$ for 15 sec, then $58^{\circ} \mathrm{C}$ for $45 \mathrm{sec}$, and hold stage at $72^{\circ} \mathrm{C}$ for $30 \mathrm{sec}$.

3- IgM/IgG COVID-19 antibody and Hematological analysis

All blood samples from patients (whole blood in EDTA tubes) were assigned to $\operatorname{IgM} / \operatorname{IgG}$ COVID-19 antibodies investigation by FREND ${ }^{\text {TM }}$ COVID-19 IgG/IgM Duo. Blood specimens of the individuals with positive rRT-PCR results for SARS-CoV-2 (99) were assigned for hematological tests, $\mathrm{C}$ - reactive protein (CRP), and WBC differential count to assess the changes in the values related to the infection and disease progression of COVID19. The tests were performed by electro-chemiluminescence immunoassay, Roche Cobas Integra 400 plus, and ABX Micros ES 60 Automated Hematology Analyzer, respectively.

4- Statistical analysis

COVID-19 antibody level and the hematological parameters were first tested for normality (Kolmogorov-Smirnova and Shapiro-Wilk test). Parameters that fit both tests (no significant difference) were given as mean \pm SD (standard deviation), and the parameters that did not fit the normality tests (significant difference) were given as median and range. The significant differences between medians were assessed by Mann-Whitney test (for comparison between two groups). The other parameters were given as percentage frequencies and significant differences between frequencies were assessed by Pearson-Chi-square test or two-tailed Fisher exact probability $(p)$. The Spearman bivariate correlation was employed to understand the correlation between certain parameters. Moreover, the multiple linear regression was applied to predict the outcome of a response variable for several explanatory variables. Receiver operating characteristic (ROC) curve was constructed for each parameter, and the area under the curve (AUC), sensitivity, and specificity were consequently estimated. The statistical package SPSS version 25.0 was employed to carry out these analyses. A value of $\mathrm{p}<0.05$ was considered statistically significant.

\section{Results and Discussion}

\section{1- Age, gender, and cycle threshold value (Ct)}

The statistical analysis showed significant $(p<0.001)$ differences between COVID-19 infections according to age group as $43.4 \%$ (43/99) of positive patients were aged $>50$ years (mean age $49.1 \pm 9.1$ year), while the ages of control were $43.8 \% \leq 40$ years old (mean age $43.02 \pm 10.258$ years), as shown in Table 1 . The data indicate that older ages are at higher risk of getting infected by COVID-19. These results confirm those of other studies that stated positive correlation between age and COVID-19 infection [7].

Table 1- Age group frequency of COVID-19 patients and control investigated in the present study.

\begin{tabular}{|c|c|c|c|c|}
\hline \multirow{2}{*}{ Age Group/ year } & \multicolumn{2}{|c|}{ COVID-19 patients (N = 99) } & \multicolumn{2}{c|}{ Control (N =96) } \\
\cline { 2 - 5 } & $\mathrm{N}$ & $\%$ & $\mathrm{~N}$ & 43.8 \\
\hline $28-40$ & 20 & 20.2 & 42 & 33.3 \\
\hline $41-50$ & 36 & 36.4 & 32 & 18.8 \\
\hline $51-60$ & 28 & 28.3 & 18 & \\
\hline
\end{tabular}




\begin{tabular}{|c|c|c|c|c|}
\hline$>60$ & 15 & 15.2 & 4 & 4.2 \\
\hline $\begin{array}{c}\text { Statistical } \\
\text { analysis }\end{array}$ & \multicolumn{4}{|c|}{ Pearson's Chi-square $=16.542 ;$ D.F. $=3 ; p=0.001$} \\
\hline
\end{tabular}

The results showed that, out of 31 critical cases, 7 death cases were recorded, all were $\geq 50$ years old. Aging is usually accompanied with comorbidities and decrease in the immune system function. A cohort study conducted in Italy on 44 SARS-COV-2 positive cases found that patients older than 60 years have a certain immune signature identified by the suppression of T-cell responses and deregulation of innate immunity, implying that age is a possible risk factor for COVID-19 infection [6].

Many studies showed a positive correlation between sex and disease outcome, males were more affected than females, as male to female infection ratio was elevated in many countries [8]. In the current study, the results also showed no significant correlation between Ct value and the patient gender (Table 2). This result could be due to gender selection of samples.

Table 2- Distribution of gender and age groups with case severity.

\begin{tabular}{|c|c|c|c|c|}
\hline \multirow{2}{*}{ Age group/ year } & \multirow{2}{*}{ Gender } & \multicolumn{3}{|c|}{ Severity Status } \\
\hline & & mild & severe & Critical (death case) \\
\hline \multirow{2}{*}{$28-40$} & Male & 4 & 0 & 1 \\
\hline & Female & 11 & 3 & 1 \\
\hline \multirow{2}{*}{$41-50$} & Male & 12 & 6 & 3 \\
\hline & Female & 10 & 4 & $1(1)$ \\
\hline \multirow{2}{*}{$51-60$} & Male & 2 & 5 & $7(1)$ \\
\hline & Female & 2 & 6 & 6 \\
\hline \multirow{2}{*}{$>60$} & Male & 0 & 2 & $8(3)$ \\
\hline & Female & 0 & 1 & $4(2)$ \\
\hline Total & & 41 & 27 & $31(7)$ \\
\hline Statistical analysis & \multicolumn{4}{|c|}{ Person Chi-square $=52.9, \mathrm{df}=2, p<0.001$} \\
\hline
\end{tabular}

The results obtained from rRT-PCR show that case severity is significantly increased when the $\mathrm{Ct}$ value is less than 30 cycle $(p<0.001)$ (Figure 1). Also, in all positive cases, the $\mathrm{Ct}$ value range was 21-35 cycle. These findings agree with most recent studies which stated that higher viral loads are inversely related to $\mathrm{Ct}$ value and leads to more severe outcome of the disease [9]. In addition, patients with high $\mathrm{HCoV}$ viral load were more likely to be co-infected with other infectious diseases, such as Tuberculosis, since co-infections are mostly found among patients with high viral load in comparison to those having a low viral load [10]. Consequently, co-infection could increase the severity of respiratory tract illness [11].

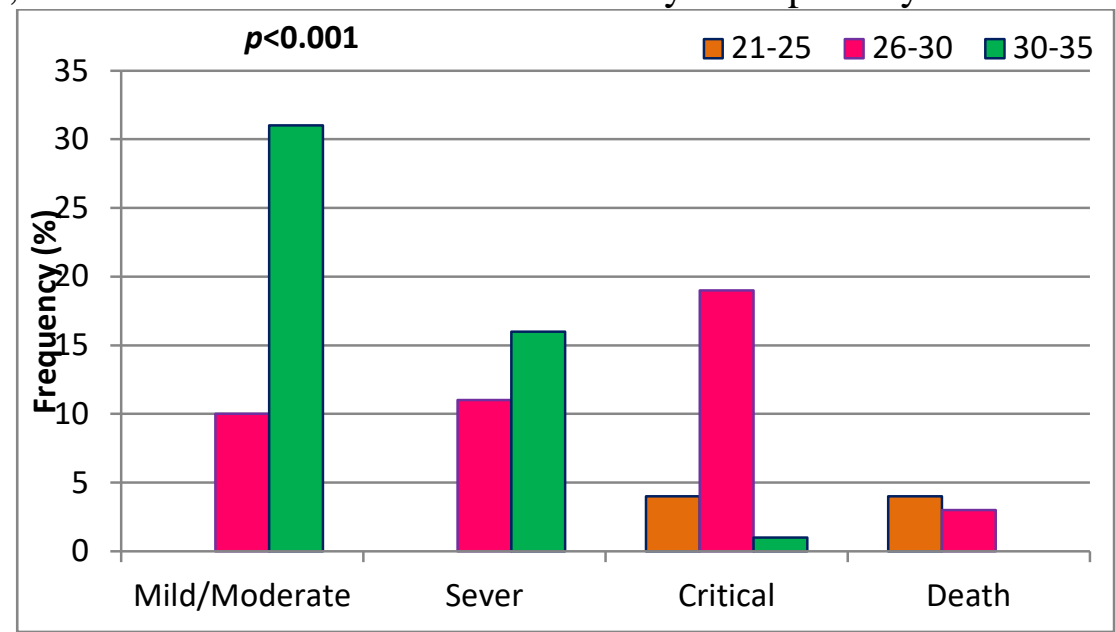

Figure 1- Frequency of $\mathrm{Ct}$ value based on rRT-PCR in relation to COVID-19 severity in Iraqi patients. 
The results obtained from the current study showed that $\mathrm{Ct}$ value and age had significant ( $p$ $<0.001$ ) inverse association, as shown in Figure 2, especially in people $>60$ years, as all cases in this group had $\mathrm{Ct}$ value lower than 30 , which agrees with many studies that implied age as a possible risk factor for COVID-19 infection [6]. COVID-19 infection manifestation seems to be in different severity degrees depending on the age of the patients, where higher risk of developing serious complications was found in older individuals [12]. A precisely balanced immune response is considered a compulsory requirement for the clearance of SARS-CoV-2 infection [13]. Usually, aging is associated with deregulation of the immune system and comorbidities. It has been reported that there is a positive correlation between hospitalization time and age, with the presence of particular cytokine profiles depending on disease severity, hospitalization time, and age of COVID-19 patients [6].

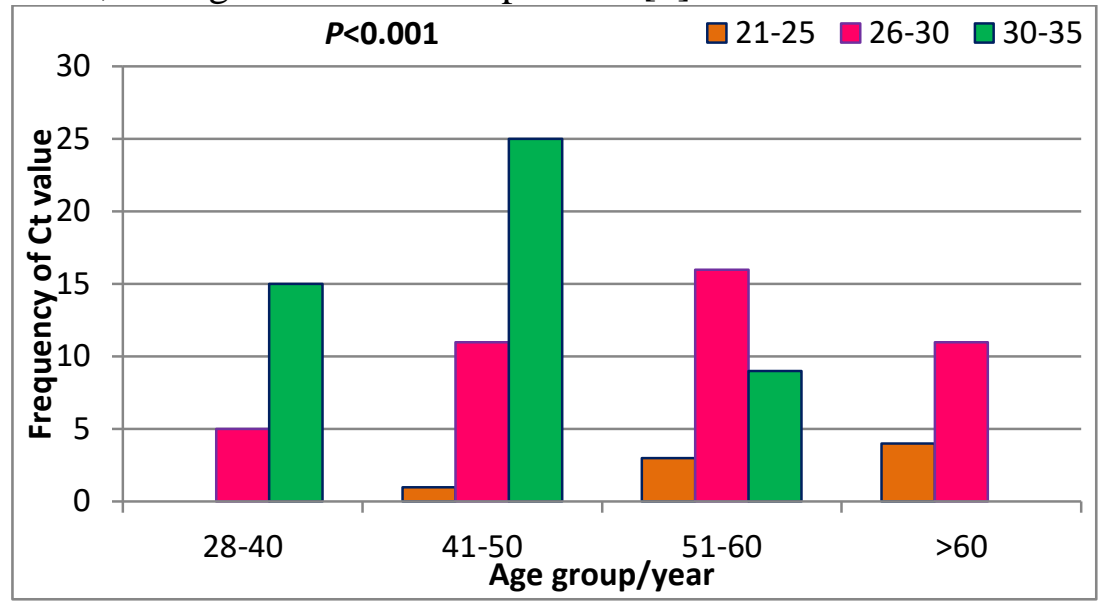

Figure 2- Frequency of $\mathrm{Ct}$ value based on rRT-PCR in relation to COVID-19 age groups in Iraqi patients.

2- Comorbidities (Hypertension and diabetes)

The results indicated a significant correlation $(p<0.001)$ in the severity of COVID-19 infection with the presence of comorbidities (diabetes and hypertension) in the severe and death cases. All death cases (7 cases) were of patients with comorbidities (Table 3).

Table 3-Distribution of COVID-19 cases between sex with comorbidities (diabetes and hypertension).

\begin{tabular}{|c|c|c|c|}
\hline \multirow{2}{*}{ Severity Status } & Sex & Hypertension & Diabetes \\
\hline \multirow{2}{*}{ mild } & Male & 4 & 6 \\
\cline { 2 - 4 } & Female & 7 & 4 \\
\hline \multirow{2}{*}{ severe } & Male & 5 & 5 \\
\cline { 2 - 4 } & Female & 8 & 9 \\
\hline \multirow{2}{*}{ Critical (death case) } & Male & $18(4)$ & $9(3)$ \\
\cline { 2 - 4 } & Female & $11(3)$ & $51(7)$ \\
\hline Total & \multicolumn{2}{|c|}{$53(7)$} \\
\hline Statistical analysis & \multicolumn{2}{|c|}{ Person Chi-square $=32.17, \mathrm{df}=2, \mathrm{p}<0.001$} \\
\hline
\end{tabular}

The Ct value showed a significant correlation $(p<0.001)$ with the presence of hypertension and diabetes, as shown in Figure 3, indicating that these comorbidities can cause a higher viral load in patients suffering from COVID-19 infection and suggesting that hypertension and diabetes represent risk factors in the patient group. This confirms the findings of an earlier study which declared that patients from Wuhan, China, with comorbid conditions had 
higher death rates of $7.3 \%$ for diabetes, $6.3 \%$ for chronic respiratory disease, $6.0 \%$ for hypertension, and $5.6 \%$ for cancer [14].

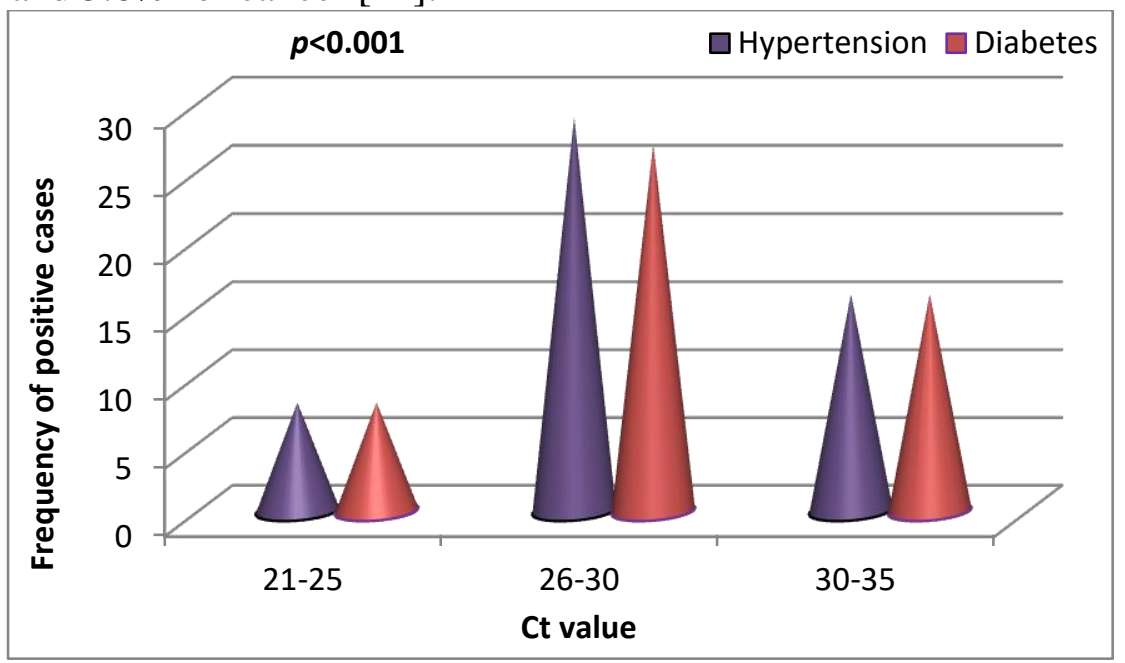

Figure 3- Frequency of positive COVID-19 cases with comorbidities in Iraqi patients in relation to $\mathrm{Ct}$ value based on $\mathrm{rRT}$-PCR.

In patients with type 1 or 2 diabetes who are treated with inhibitors of ACE and angiotensin II type-I receptor blockers (ARBs), the expression of angiotensin- converting-enzyme 2 is highly increased. ACE inhibitors and ARBs are also used for hypertension treatment, which causes an ACE2 upregulation. Also, since ACE2 is a main receptor of SARS-COV-2, then the increased expression of ACE2 would facilitate infection with COVID-19 [15].

\section{3- Hematological parameters}

Antibody test results showed a rise in IgM levels with a median of 0.9800 and a range of 2.93-32.48. In addition, no significant rise in IgG levels was observed, with a median of 0.5500 and a range of $0.21-0.65$. This confirms the outcomes of many studies which revealed that SARS-CoV-2 IgM antibody response appeared earlier and peaked earlier than the IgG antibody response [16]. IgM was reported to reach its peak at early stages, while IgG reached its peak during 21 to 25 days after illness onset, and stayed at a relatively high level until 31 41 days [17]. IgM antibodies provide early stage defense during viral infections before the development of the class IgG response for long term immunity and immunological memory [18]. At the time of the SARS outbreak, numerous reports showed that the identification of viral specific $\operatorname{IgM}$ and $\operatorname{IgG}$ is valid for serological diagnosis [19]. Although it is not recommended to use immunological tests exclusively for the diagnosis of COVID-19 infection, antibody tests are considered as supplementary but necessary in several applications. These include diagnosis of suspected cases that have a negative viral RNA test or previous infection of COVID-19, observation and epidemiological assessment at a population level, from which the actual case fatality rate CFR can be established and according to which medical resource can be distributed, development and evaluation of therapeutic antibody and vaccine, surveillance of immune responses to assess the degree, course, and longevity of immunity, determination of probable convalescent plasma donors, and contact tracing to detect the subsequent chains of events and specify clusters of cases [20].

The results showed a significant rise $(p<0.001)$ in neutrophil count and CRP levels in the older groups of patients. In addition, the results revealed a decrease in platelets and lymphocyte counts and a rise in monocyte counts in all age groups (Table 4). These findings are in agreement with a study from China conducted on 1099 confirmed cases of COVID-19, which found that the vast majority of patients presented with lymphocytopenia $(83.2 \%)$, 
whereas $36.2 \%$ had thrombocytopenia and $33.7 \%$ showed leukopenia [8]. Another study from China stated that CRP was elevated in $60.7 \%$ of the COVID-19 patients [3].

Table 4-Distribution of hematological test results ( $>$ median and $\leq$ median) in COVID-19 patients according to age groups.

\begin{tabular}{|c|c|c|c|c|c|c|c|}
\hline \multirow[t]{2}{*}{ Test } & \multirow[t]{2}{*}{ Median } & \multicolumn{4}{|c|}{ No. of cases in Age group/year } & \multirow[t]{2}{*}{ Median (range) } & \multirow[t]{2}{*}{ P value } \\
\hline & & $28-40$ & $41-50$ & $51-60$ & $>60$ & & \\
\hline \multirow[t]{2}{*}{ CRP } & $>$ Median & 6 & 11 & 20 & 12 & \multirow[t]{2}{*}{$15.8(19.60-126.30)$} & \multirow[t]{2}{*}{$<0.001$} \\
\hline & $\leq$ Median & 14 & 25 & 8 & 3 & & \\
\hline \multirow[t]{2}{*}{ Platelets } & $>$ Median & 14 & 24 & 10 & 1 & \multirow[t]{2}{*}{$193.0(84-475)$} & \multirow[t]{2}{*}{$<0.001$} \\
\hline & $\leq$ Median & 6 & 12 & 18 & 14 & & \\
\hline \multirow[t]{2}{*}{ Lymphocyte } & $>$ Median & 14 & 22 & 6 & 2 & \multirow[t]{2}{*}{$37.00(11-56)$} & \multirow[t]{2}{*}{$<0.001$} \\
\hline & $\leq$ Median & 6 & 14 & 22 & 13 & & \\
\hline \multirow[t]{2}{*}{ Monocyte } & $>$ Median & 10 & 19 & 13 & 6 & \multirow[t]{2}{*}{$2.00(3-7)$} & \multirow{2}{*}{$\begin{array}{l}0.858 \\
(\mathrm{NS})\end{array}$} \\
\hline & $\leq$ Median & 10 & 17 & 15 & 9 & & \\
\hline \multirow[t]{2}{*}{ Neutrophil } & $>$ Median & 4 & 11 & 17 & 11 & \multirow[t]{2}{*}{$60.00(12-59)$} & \multirow[t]{2}{*}{0.002} \\
\hline & $\leq$ Median & 16 & 25 & 11 & 4 & & \\
\hline \multirow[t]{2}{*}{ Basophile } & $>$ Median & 8 & 10 & 4 & 5 & \multirow[t]{2}{*}{$.00(1-1)$} & \multirow{2}{*}{$\begin{array}{l}0.231 \\
(\mathrm{NS})\end{array}$} \\
\hline & $\leq$ Median & 12 & 26 & 24 & 10 & & \\
\hline \multirow[t]{2}{*}{ Eosinophil } & $>$ Median & 10 & 6 & 8 & 6 & \multirow[t]{2}{*}{$1.00(2-34)$} & \multirow{2}{*}{$\begin{array}{l}0.056 \\
\text { (NS) }\end{array}$} \\
\hline & $\leq$ Median & 10 & 30 & 20 & 9 & & \\
\hline
\end{tabular}

p: Probability, NS: Not significant $(p>0.05)$, normal values of CRP: $\leq 5 \mathrm{mg} / \mathrm{l}$, Platelets:150400, Lymphocyte: 18-45, Monocyte: 2-8, Neutrophil: 40-75, Basophile: 0-2, Eosinophil: 0-7.

Many factors may contribute to COVID-19-associated lymphopenia. SARS-CoV-2 may directly infect lymphocytes and ultimately lead to their lysis, as it was shown that these cells express the ACE2 receptor on their surface [21]. Moreover, cytokine storm is characterized by markedly increased levels of interleukins and tumor necrosis factor alpha (TNF $\alpha$ ), which may promote lymphocyte apoptosis [22]. Thrombocytopenia as a response to viral infections that is usually mediated through enhanced clearance and destruction of platelets. Platelets can be activated by viral antigen-antibody complexes or host inflammatory responses, Platelets interact directly with viruses via a variety of receptors. Viruses can also interact with megakaryocytes and reduce platelet synthesis [23].

Neutrophilia importance rises during neutrophil degranulation and release of neutrophil extracellular traps NETs, along with the continuous neutrophils infiltration at the site of infection in response to microbial stimuli. To set up an immune response, these cells produce exaggerated amounts of cytokines and chemokines that may result in the cytokine storm and contribute to acute respiratory distress syndrome (ARDS), systemic inflammatory response syndrome (SIRS), and sepsis development during COVID-19 infection [24].

C- reactive protein is an indirect test for inflammation, having both proinflammatory and anti-inflammatory properties. It can activate phagocytic cells as well as the classic complement pathway. In certain cases, it can worsen the tissue damage by the activation of the complement system and thus inflammatory cytokines [25]. Therefore, monitoring CRP levels in COVID-19 patients has a potential benefit of predicting the case progression.

Figure 4 demonstrates an increase in the neutrophil to lymphocyte ratio that corresponds with the elevated severity of disease. This agrees with most recent studies which declared increases in neutrophil count and NLR, usually indicatingm higher disease severity and poor clinical outcome [26]. 


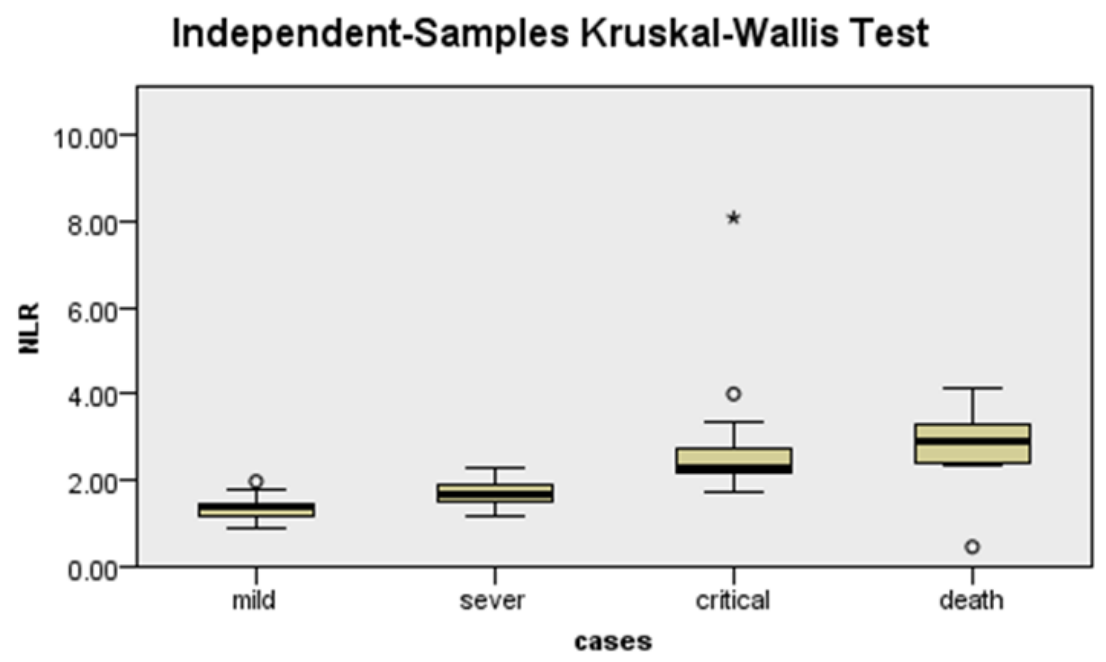

Figure 4-Box-plot presentation of Neutrophil Lymphocyte Ratio (NLR) in blood of COVID19 patients with different severity of cases $(* p<0.001)$.

Neutrophil to lymphocyte ratio for COVID-19 patients is predicting subsequent disease deterioration, critical cases, and death. NLR results showed lower values in mild COVID-19 infection than severe cases (median: $1.36 \mathrm{VS} 1.65, p<0.05$ ). The values were higher in patients with deterioration and death than those in critical clinical status and survivals (median: 2.91 VS 2.27, $p<0.001$ ).

Our findings declare that NLR is a good biomarker for patients with COVID-19 infection. The ROC analysis revealed AUC value of 0.813 , with a range from 0.5 to 1.0. Also, the results demonstrated associated sensitivity $(\%)=85.7$, specificity $(\%)=75.0$, cut-off value $=1.346$, and $p$ value $=0.006$, as appears in Figure 5. This implies that NLR could be a useful biomarker and potential prognostic factor. This confirms the outcomes of a retrospective study on 68 confirmed SARS-CoV-2 infection patients, which declared that NLR could be a valuable parameter for the identification of patients at high risk for developing severe disease outcome, as the NLR showed superior prediction among other hematological parameters of disease severity. The authors also reported that the NLR optimal cutoff value was calculated as 3.63, AUC was 0.948 , with a sensitivity of $93.5 \%$ and a specificity of $72.7 \%$ [27]. These results correspond with suggestions from many other studies. Overall, higher neutrophil count, NLR, and CRP levels may be potential prognostic factors for SARS-CoV infections [28].

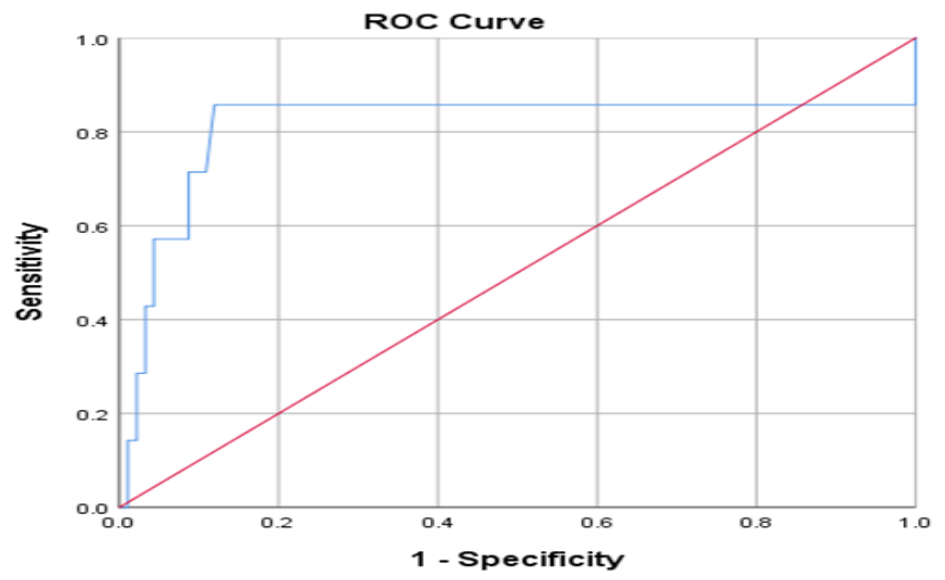

Figure 5-Receiver operating characteristic analysis (area under curve) of Neutrophil to Lymphocyte Ratio (NLR) among COVID-19 patients (red line=reference line, blue line= NLR). 
Our findings suggest that individuals with older ages are at higher risk, especially people with comorbidities (HT and diabetes). Also, higher death ratio was recorded in patients of older ages with pre-existing conditions. Also, higher neutrophil counts and NLR could be useful biomarkers and potential prognostic factors, confirming the importance of laboratory records in assessing case severity and disease progression.

\section{References}

[1] C. Huang et al., "Clinical features of patients infected with 2019 novel coronavirus in Wuhan, China", The Lancet, vol. 395, no. 10223, pp. 497-506, 2020. Available: 10.1016/s0140-6736(20)30183-5.

[2] N. Chen et al., "Epidemiological and clinical characteristics of 99 cases of 2019 novel coronavirus pneumonia in Wuhan, China: a descriptive study", The Lancet, vol. 395, no. 10223, pp. 507-513, 2020. Available: 10.1016/s0140-6736(20)30211-7.

[3] W. Guan et al., "Clinical Characteristics of Coronavirus Disease 2019 in China", New England Journal of Medicine, vol. 382, no. 18, pp. 1708-1720, 2020. Available: 10.1056/nejmoa2002032.

[4] X. Sun et al., "Cytokine storm intervention in the early stages of COVID-19 pneumonia", Cytokine \& Growth Factor Reviews, vol. 53, pp. 38-42, 2020. Available: 10.1016/j.cytogfr.2020.04.002.

[5] G. Ponti, M. Maccaferri, C. Ruini, A. Tomasi and T. Ozben, "Biomarkers associated with COVID-19 disease progression", Critical Reviews in Clinical Laboratory Sciences, vol. 57, no. 6, pp. 389-399, 2020. Available: 10.1080/10408363.2020.1770685.

[6] R. Angioni et al., "Age-severity matched cytokine profiling reveals specific signatures in Covid-19 patients", Cell Death \& Disease, vol. 11, no. 11, 2020. Available: 10.1038/s41419-020-03151-z.

[7] Q. Bi et al., "Epidemiology and transmission of COVID-19 in 391 cases and 1286 of their close contacts in Shenzhen, China: a retrospective cohort study", The Lancet Infectious Diseases, vol. 20, no. 8, pp. 911-919, 2020. Available: 10.1016/s14733099(20)30287-5.

[8] G. Sharma, A. Volgman and E. Michos, "Sex Differences in Mortality From COVID-19 Pandemic", JACC: Case Reports, vol. 2, no. 9, pp. 1407-1410, 2020. Available: 10.1016/j.jaccas.2020.04.027.

[9] L. Zou et al., "SARS-CoV-2 Viral Load in Upper Respiratory Specimens of Infected Patients", New England Journal of Medicine, vol. 382, no. 12, pp. 1177-1179, 2020. Available: 10.1056/nejmc2001737.

[10]H. Salah, H. Fadhil and F. Alhamdani, "Multiplex Sybr Green Assay For Coronavirus Detection Using Fast Real-Time Rt-Pcr", Iraqi Journal Of Agricultural Sciences, vol. 51, no. 2, pp. 556-564, 2020a. Available: 10.36103/ijas.v51i2.982.

[11]H. Salah, I. Aufi, H. Fadhil and F. Alhamdani, "Human Coronavirus Species and their correlation as co-infection detected by Fast Real-Time RT-PCR", Research Journal of Pharmacy and Technology, vol. 13, no. 6, p. 2578, 2020b. Available: 10.5958/0974360x.2020.00459.x.

[12]A. Akbar and D. Gilroy, "Aging immunity may exacerbate COVID-19", Science, vol. 369, no. 6501, pp. 256-257, 2020. Available: 10.1126/science.abb0762.

[13]C. Qin et al., "Dysregulation of Immune Response in Patients With Coronavirus 2019 (COVID-19) in Wuhan, China", Clinical Infectious Diseases, vol. 71, no. 15, pp. 762768, 2020. Available: 10.1093/cid/ciaa248.

[14]Z. Wu and J. McGoogan, "Characteristics of and Important Lessons From the Coronavirus Disease 2019 (COVID-19) Outbreak in China", JAMA, vol. 323, no. 13, p. 1239, 2020. Available: 10.1001/jama.2020.2648. 
[15]L. Fang, G. Karakiulakis and M. Roth, "Are patients with hypertension and diabetes mellitus at increased risk for COVID-19 infection?", The Lancet Respiratory Medicine, vol. 8, no. 4, p. e21, 2020. Available: 10.1016/s2213-2600(20)30116-8.

[16]X. Liu, J. Wang, X. Xu, G. Liao, Y. Chen, and C.-H. Hu, "Patterns of IgG and IgM antibody response in COVID-19 patients," Emerging Microbes \& Infections, vol. 9, no. 1, pp. 1269-1274, 2020.

[17]H. Ma, W. Zeng, H. He, D. Zhao, D. Jiang, P. Zhou, L. Cheng, Y. Li, X. Ma, and T. Jin, "Serum IgA, IgM, and IgG responses in COVID-19," Cellular \& Molecular Immunology, vol. 17, no. 7, pp. 773-775, 2020.

[18]G. Li, X. Chen, and A. Xu, "Profile of Specific Antibodies to the SARS-Associated Coronavirus," New England Journal of Medicine, vol. 349, no. 5, pp. 508-509, 2003.

[19]F. Xiang, X. Wang, X. He, Z. Peng, B. Yang, J. Zhang, Q. Zhou, H. Ye, Y. Ma, H. Li, X. Wei, P. Cai, and W.-L. Ma, "Antibody Detection and Dynamic Characteristics in Patients With Coronavirus Disease 2019," Clinical Infectious Diseases, vol. 71, no. 8, pp. 19301934, 2020.

[20]G. Liu and J. F. Rusling, "COVID-19 Antibody Tests and Their Limitations," ACS Sensors, vol. 6, no. 3, pp. 593-612, 2021.

[21] Y. Xu, M. Xiao, X. Liu, S. Xu, T. Du, J. Xu, Q. Yang, Y. Xu, Y. Han, T. Li, H. Zhu, and M. Wang, "Significance of serology testing to assist timely diagnosis of SARS-CoV-2 infections: implication from a family cluster," Emerging Microbes \& Infections, vol. 9, no. 1, pp. 924-927, 2020.

[22] S. Singh, A. Sharma, and S. K. Arora, "High Producer Haplotype (CAG) of -863C/A, 308G/A and -238G/A Polymorphisms in the Promoter Region of TNF- $\alpha$ Gene Associate with Enhanced Apoptosis of Lymphocytes in HIV-1 Subtype C Infected Individuals from North India," PLoS ONE, vol. 9, no. 5, 2014.

[23] M. Seyoum, B. Enawgaw, and M. Melku, "Human blood platelets and viruses: defense mechanism and role in the removal of viral pathogens," Thrombosis Journal, vol. 16, no. $1,2018$.

[24] Y. Zuo, M. Zuo, S. Yalavarthi, K. Gockman, J. A. Madison, H. Shi, J. S. Knight, and Y. Kanthi, "Neutrophil extracellular traps and thrombosis in COVID-19," 2020.

[25] S. M. Nehring, "C Reactive Protein," StatPearls [Internet]., 10-May-2021. [Online]. Available: https://www.ncbi.nlm.nih.gov/books/NBK441843/. [Accessed: 26-May2021].

[26] M. Zheng, Y. Gao, G. Wang, G. Song, S. Liu, D. Sun, Y. Xu, and Z. Tian, "Functional exhaustion of antiviral lymphocytes in COVID-19 patients," Cellular \& Molecular Immunology, vol. 17, no. 5, pp. 533-535, 2020.

[27] S. Lin, W. Mao, Q. Zou, S. Lu, and S. Zheng, "Associations between hematological parameters and disease severity in patients with SARS-CoV-2 infection," Journal of Clinical Laboratory Analysis, vol. 35, no. 1, 2020.

[28] J. Wang, Q. Li, Y. Yin, Y. Zhang, Y. Cao, X. Lin, L. Huang, D. Hoffmann, M. Lu, and Y. Qiu, "Excessive Neutrophils and Neutrophil Extracellular Traps in COVID-19," SSRN Electronic Journal, 2020. 